\title{
Cartel soviético de la época postrevolucionaria (1917-1932)
}

Soviet poster of the post-revolutionary era (1917-1932)

Ekaterina Yashina

Departamento de Historia del Arte, Universidad de Málaga, España (kaaty.993@gmail.com)

Recibido el 16 de junio de 2017; revisado el 28 de junio de 2017; aceptado el 14 de julio de 2017; publicado el 01 de septiembre de 2017

RESUMEN: Este artículo tiene como objetivo acercar al lector al cartel soviético como forma de expresión artística. Para comprender la relevancia del cartel soviético es necesario hacer una aproximación al contexto en el que se desarrolla. Los artistas se encuentran al servicio del Estado y su función es hacer llegar su mensaje a toda la población. El arte gráfico soviético destaca por el empleo de cartel de agitación como medio para difundir la ideología bolchevique, y como toda forma artística, tiene unos antecedentes, en ocasiones, inesperados. El arte tradicional ruso se convierte en el punto de partida para el desarrollo de los carteles. Los artistas se sumergen en la investigación y redescubrimiento de sus propias raíces, potenciándolas y reforzándolas y, de este modo, se produce un acercamiento a la sociedad rusa a través de elementos que ya conocen.

PALABRAS CLAVE: Propaganda, Revolución, Arte Gráfico, Icono, Lubok.

ABSTRACT: This article aims to bring the reader to the Soviet poster as a form of artistic expression. To understand the relevance of the Soviet cartel is necessary to approach the context in which it develops. The artists are at the service of the State and their function is to get their message across the entire population. The Soviet graphic art stands out for the use of a poster of agitation as a way to spread the Bolshevik ideology, and as any artistic form, it has sometimes unexpected antecedents. Russian traditional art becomes the starting point for the development of posters. Artists are immersed in the research and rediscovery of their own roots, enhancing and reinforcing them and, in this way, an approach to Russian society is produced through elements that already know.

KEYWORDS: Propaganda, Revolution, Graphic Art, Icon, Lubók. 
Las décadas de 1910 a 1930 vienen a determinar la integración de las artes plásticas con la política. La efervescencia de estilos y corrientes de la época retumban y consiguen trascendencia a través de los años. En los años posteriores a la Revolución de 1917 se gestan muchos nuevos cambios en Rusia.

La Revolución de Octubre, sin duda, fue el mayor detonante en el cambio de puntos de vista socio-políticos y artísticos. El proletariado resurge como ser humano, se abole el Antiguo Régimen y se fusilan a los últimos miembros de la familia real, los Románov. Nace una nueva sociedad que, dirigida por los bolcheviques, aspira a la libertad, dejándose llevar por las ideas marxistas de Lenin (Bozal, 1978, p.138). El concepto de arte, tal como se conocía hasta entonces, se pone en cuestión y comienza la búsqueda de un arte acorde a la nueva sociedad proletaria revolucionaria mientras la vida artística estaba influenciada por la ideología y la política del poder soviético. Entonces surgieron grupos independientes con proyectos innovadores y extraordinarias obras de arte (Tolstoi, 2010, p.10).

Tras la Revolución se produce la pérdida del mercado privado y los artistas que anteriormente vendían obras a coleccionistas privados tuvieron que buscar ahora nuevas formas, siendo una de las opciones trabajar para la administración de las artes del nuevo Ministerio de Cultura NARKOMPROS. Los años revolucionarios fomentaron la creación de nuevas formas de expresión, durante los cuales, un desarrollo interesante fue el de arte de agitación: monumentos, decoración de las calles durantelas festividades revolucionarias, carteles y eslóganes (Tolstoi, 2010, p.13).

\section{Definición e importancia del cartel soviético}

Para poder contestar a la pregunta de qué es un cartel, hay que tener en cuenta que dicha palabra posee diversos significados, dentro de los cuales seleccionamos las siguientes definiciones que propone la Real Academia Española1.

Del occit. cartel.

1. m. Lámina en que hay inscripciones o figuras y que se exhibe confines informativos o publicitarios.

2. m. Lámina con grandes caracteres que sirve en las escuelas para enseñar a leer.

3. m. Pasquín (\| escrito anónimo).

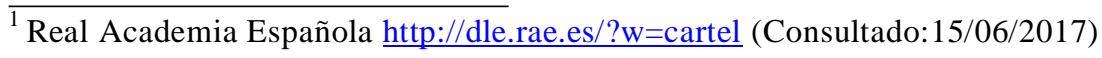


Un cartel es una forma de comunicación visual o propaganda muy particular, para lo cual se necesitan cuidar todos los detalles, tanto en el color empleado como en el mensaje a transmitir y ambos deben ser bastante lacónicos. El mensaje (que puede ser una imagen, una consigna/llamamiento o ambos a la vez) suele jugar con diversas figuras literarias como, por ejemplo, la metáfora o la hipérbole (Kurz Muñoz, 1991, p.70).

Desde sus inicios, el cartel ha tenido una función publicitaria e informativa y ha sido considerado un arte secundario, muy ligado a la pintura y a estilos decorativos de moda. Sin embargo, este sufre un cambio tras las Primera Guerra Mundial. Según Barnicoat, el cartel político y la historia de los medios de comunicación evolucionan en aquellos años en Rusia (1972, p.223). En los carteles de la nueva época, la época postrevolucionaria, se representaba la sociedad en convulsión, la que estaba creando nuevos estereotipos y nuevas ocupaciones laborales. El cartel político se popularizó, sobre todo, en la Revolución de Octubre, transmitiendo las ideas de la Revolución a las masas populares de manera sencilla y directa (Kurz Muñoz, 1991, p.67). Durante las épocas de carencias se generó una escasez de materiales, lo cual dificultó la elaboración de los carteles y afectó a su calidad, pero sin condicionar el mensaje que se quería transmitir. Los carteles se reproducían en miles ejemplares y transmitían imágenes con eslóganes que apelaban a los valores cívicos del momento.

¿Cómo se difundían los carteles? El periódico Pravda (Verdad) informaba sobre los nuevos carteles de agitación que salían a la luz, convirtiéndose en un símbolo, sobre todo, de los bolcheviques (Kenez, 1985, p. 32). Y una gran mayoría de los carteles del momento también invadían las calles de las ciudades soviéticas, casas, fábricas, estaciones de autobús, es decir, estaban por todas partes y ejercían una gran influencia en la población. En 1919, aparece una nueva forma de cartel: Okna ROSTA (Ventanas de la Agencia de Noticias Telegráfica Rusa) (Büchten, 2012, p. 8). Los carteles de Okna ROSTA salían publicados en un boletín y sus ilustraciones estaban enumeradas, lo cual permite tener una secuencia y crear una historieta. Los primeros carteles se hicieron manualmente y en ejemplares únicos, pero posteriormente fueron reproducidos por estarcido. Maiakovsky, un poeta futurista ruso, fue uno de los creadores de las viñetas más interesantes [1]. Los carteles de Okna ROSTA combinan imágenes de color con un breve texto, siguiendo la tradición de los lubkí, se describirán detalladamente más adelante. ¿Por qué los carteles de Okna ROSTA se llamaban así? Al comienzo se llamaban periódicos de pared de ROSTA, pero debido a su constante colocación en las ventanas de diversos locales, además de paredes urbanas, fue adquiriendo ese nuevo nombre que mejor se adaptaba a sus características. 


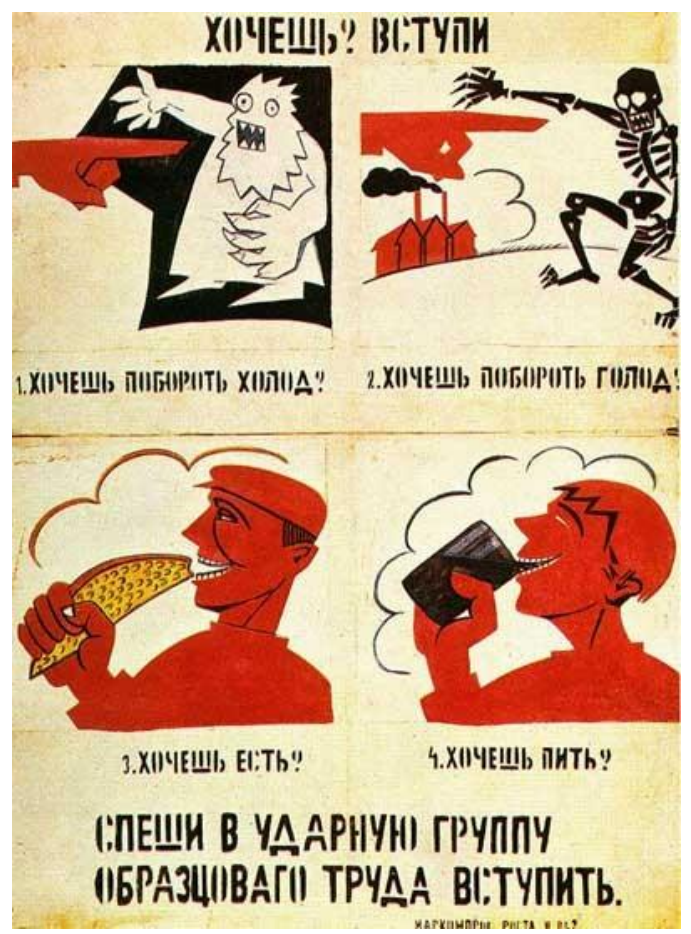

[Fig. 1] Maiakovsky - ¿Quieres? Apúntate (1921). Fuente:

https://upload.wikimedia.org/wikipedia/commons/1/11/Plakat_mayakowski_gross.jpg (Consultado: 15/06/17)

Desde la implantación de NEP (Nueva Política Económica) por Lenin, en 1921 y hasta 1928, el cartel ejerce un papel muy significativo para promover la voluntad del partido. Una de las características de ese periodo es la representación de la sociedad con un espíritu partidario y orgulloso del Estado, aceptando todas las obligaciones que deben realizar. En el año 1928, cuando comienza el primer Plan Quinquenal2 (1928-1932), el cartel se orienta hacia la divulgación y animación de la sociedad para cumplir los objetivos propuestos. Había dos objetivos principales en el primer plan: la industrialización y la colectivización de la agricultura (Tupitsyn, 1996, p. 8). Se genera un aumento en los puestos de trabajo para las mujeres en las fábricas, y es de esta forma como ellas son representadas en los carteles: como mujeres - ingenieras y trabajadoras (Büchten, 2012, p.8).

Tras la toma de poder por los bolcheviques en 1917, se estableció el nuevo Estado Soviético, dentro del cual el cartel jugó un papel relevante en el nuevo Estado, el cual, además, ya fue empleado desde comienzos de la Revolución para difundir las ideas bolcheviques. La importancia que adquirió

\footnotetext{
${ }^{2}$ El Plan Quinquenal es un proyecto que promueve Stalin y que tiene una duración de cinco años en el que se ponen diferentes objetivos a cumplir para una mejora en el país. En la Unión Soviética estos planes Quinquenales durarán hasta 1991, con la caída de la Unión. Cada Plan Quinquenal perseguirá diferentes objetivos, los cuales sobre todo tienen que ver con la industrialización, electrificación, colectividad agraria o exportaciones de productos agrarios, entre otros.
} 
el cartel fue advertida por dos grandes teóricos. Polonsky Viatcheslav, reconocido teórico y crítico soviético, afirma que el cartel: "Exige, llama, manda, tiraniza. El cartel es un arma de las masas, un medio de la organización de la psicología colectiva" (1925, p. 9). E incluso el propio Engels veía en él un rol importante: "El cartel es el medio más efectivo para el proletario" (Chaus, 2010, p.14).

Durante la Revolución, el cartel fue un soldado más de la misma y, con los bolcheviques, los carteles de ROSTA, se copiaban a mano y se repartían por las grandes ciudades. La economía política de los bolcheviques llevó a gran población a la hambruna y, por consiguiente, la muerte, por ello, el cartel tenía la función de avisar las nuevas de la guerra, la llegada de alimentos o la prevención de las epidemias. En Rusia de los años de la Revolución, gran parte de población era analfabeta. No hay que olvidar que era un país bastante atrasado industrialmente y el principal sustento del país era la agricultura o la ganadería, por lo que, desde pequeños, los niños aprendían antes a ordeñar una vaca que a leer o escribir. Por tanto, las formas de expresión visuales tenían gran poder y facilidad para llegar a ese porcentaje de población, convirtiéndose el cartel, en el medio idóneo para difundir la nueva ideología, el nuevo sistema de valores, la manera de comportarse y normas de convivencia (Chaus, 2010, p. 14).

\section{Antecedentes del cartel soviético: icono y lubók}

El cartel no pretende representar el mundo tal como lo ve, no persigue un realismo, sino que es, por lo general, es una obra gráfica plana y muy alejada del concepto de "perspectiva albertiana"(Tarabukin, 1923, p. 40).

Los iconos y los lubkí son los antecedentes más destacados del cartel. Son imágenes populares que junto a un texto se utilizaban en Rusia desde la antigüedad: desde el siglo X, los iconos y desde el siglo XVII los lubkí. Ambos formaron una parte relevante en la vida del pueblo llano ruso, por tanto, la utilización de los carteles continúa con la tradición de funcionalidad que éstos tuvieron, sólo que la estética que presenta el cartel, así como sus medios de producción, son distintos. (Leclanche-Boulé C., 2003, p. 56). Camila Gray señala la influencia que tienen el icono y el lubók en los pintores de la prevanguardia rusa, como Natalia Goncharova y Mijaíl Lariónov, quienes se sentían atraídos por el arte tradicional ruso, en especial por los lubkí y los iconos (1971, p.97). Mientras en Europa los pintores buscaban el primitivismo en lugares más remotos, los artistas rusos se giran hacia sus propias raíces y conforman una corriente artística llamada el primitivismo ruso. 


\section{El lubók}

¿Qué es el lubók? Es un grabado tradicional ruso que se populariza a partir del siglo XVII. El lubók (en plural lubkî) se puede considerar uno de los antecedentes del cartel soviético, no solo por su estética sino también por su función: entretener a la población, difundir un mensaje o enseñar a través de representaciones visuales para el pueblo analfabeto del momento (Andreeva, 2009, p. 195). El lubók hace referencia a la madera utilizada para tallar los grabados, generalmente la corteza del tilo que se llamaba $l u b$. La madera era el material más empleado en Rusia para los grabados, si bien, también se emplearon las planchas de metal.

En el siglo XIX y principios del XX, lubók deja de ser un arte primitivo y "malelaborado", resurgiendo como inspiración para los artistas contemporáneos de la época y retomando ese arte de grabado para realizar sus obras. De este modo, recuperan el arte popular (lubok, rótúlos antiguos, decoración floral - jojlomá, etc.) el cual, hasta ese momento, no era considerado una expresión culta ni académica.

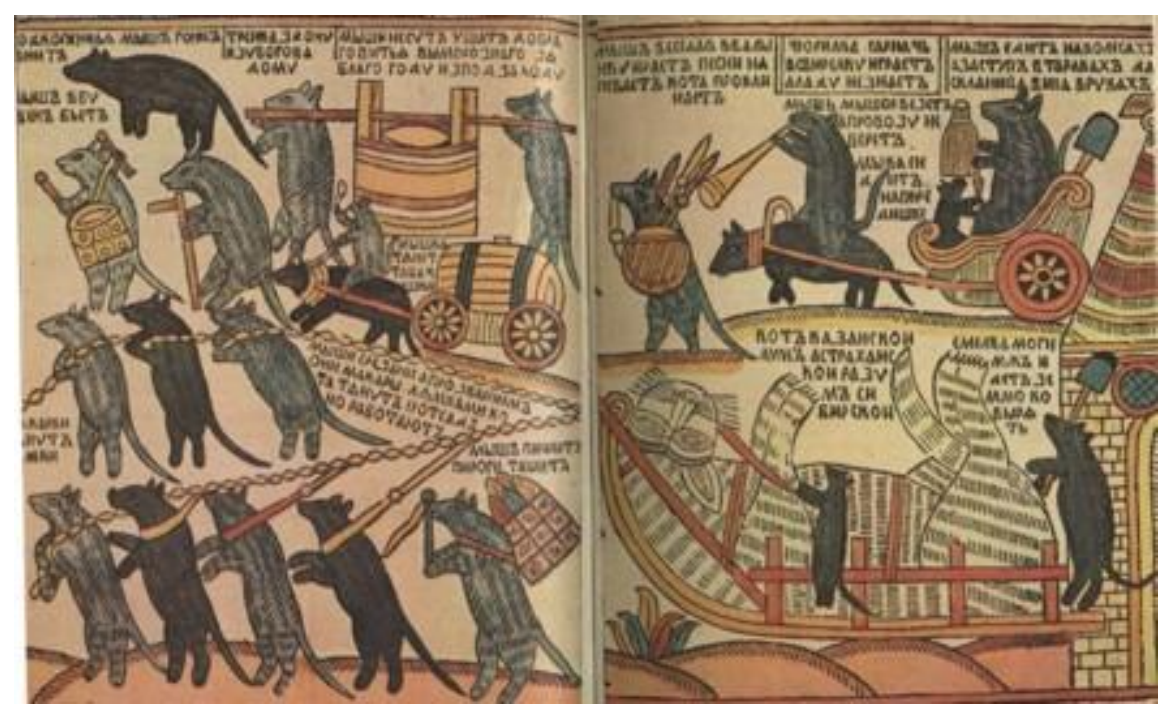

[Fig. 2] Anónimo - Los ratones entierran al gato (1760). Fuente: https://es.wikipedia.org/wiki/Lubok\#/media/File:Miceburying-the-cat.jpg (Consultado: 15/06/2017)

El lubok se componía de tres partes: el título, imagen y el texto [2]. Normalmente eran xilografías que representaron diversos temas, como religión, acontecimientos importantes, personajes históricos, avances científicos y tecnológicos, cotidianeidad, fábulas y sátiras, de manera didáctica. 
Parece que tiene una línea temática sencilla, pero lo cierto es que esconde un doble sentido como, por ejemplo, la sátira, que mayoritariamente iba dirigida a los habitantes de otras regiones o a los mismísimos reyes o reinas, como es el caso de Pedro el Grande y Catalina la Grande (Andreeva, 2009, p.196).

El texto ayuda a la comprensión del dibujo, pero no hay que olvidar que, en el siglo XVI, época en la que comenzó a expandirse el lubók, solo unos pocos sabían leer. Por lo tanto, los lubók se convertían en una especie de teatro callejero donde el orador interpretaba lo escrito. El texto y la imagen se unifican y dependen uno del otro. Su empleo, por tanto, podía ser diverso y sus funciones se compartían con otras formas de expresión folklóricas, a diferencia del lubki, cuyo cometido era el de la propaganda y la información. Por ejemplo, durante el reinado de Pedro el Grande y Catalina la Grande, los lubkí se utilizaron para publicitar la vacuna contra la viruela y también se difundió el recordatorio sobre la victoria del imperio ruso contra los turcos. Y durante la guerra con Napoleón, el lubók fue un gran aliado para hacer burlas sobre el ejército francés y el propio Napoleón (Hilton A., 2011, p. 107-112).

Volviendo a la época soviética, y a la llegada de los bolcheviques, se proclama el monopolio de los medios de comunicación: se prohíbe cualquier publicación que vaya en contra de la ideología, acaparan el correo, el teléfono y el telégrafo. Además, se prohíbe la publicación de los lubkí sin carga política. El cartel se convierte en una fiebre mediática de propagación ideológica.

\section{El icono}

Los iconos son representaciones procedentes de la cultura y el arte Bizantino, que fueron traídos a Rusia cuando esta se empezó a expandir. Se caracterizan, principalmente, por un aplanamiento de las figuras: predominaba la ausencia de profundidad y de volumen, la representación frontal de las figuras y se empleaba una jerarquización, según la importancia de los personajes representados. Otra de las características es la pervivencia del estilo medieval en ellos, aunque con algunas innovaciones. Se solían representar sobre madera (Papaioannou, 1968, p. 62).

¿Qué heredaron los carteles soviéticos de los iconos ortodoxos? A partir de una análisis formal del ícono, se puede notar que está realizado con una planitud remarcable y sus personajes no evocan perspectiva ni profundidad [3]. Por otra parte, el color es plano también y no se realizan degradaciones cromáticas y los tonos suelen ser uniformes. Y si se hace una comparativa, el cartel adquiere estas 
características. La gama cromática es limitada y el color rojo es el más utilizado, ya que se ha convertido en el color identificativo de los bolcheviques. Es el color de la sangre, del sufrimiento y de la lucha por el poder y la libertad. También se hereda del icono el contorneado de las formas que, sobre todo, se pueden ver en los primeros carteles o los carteles de okna ROSTA.

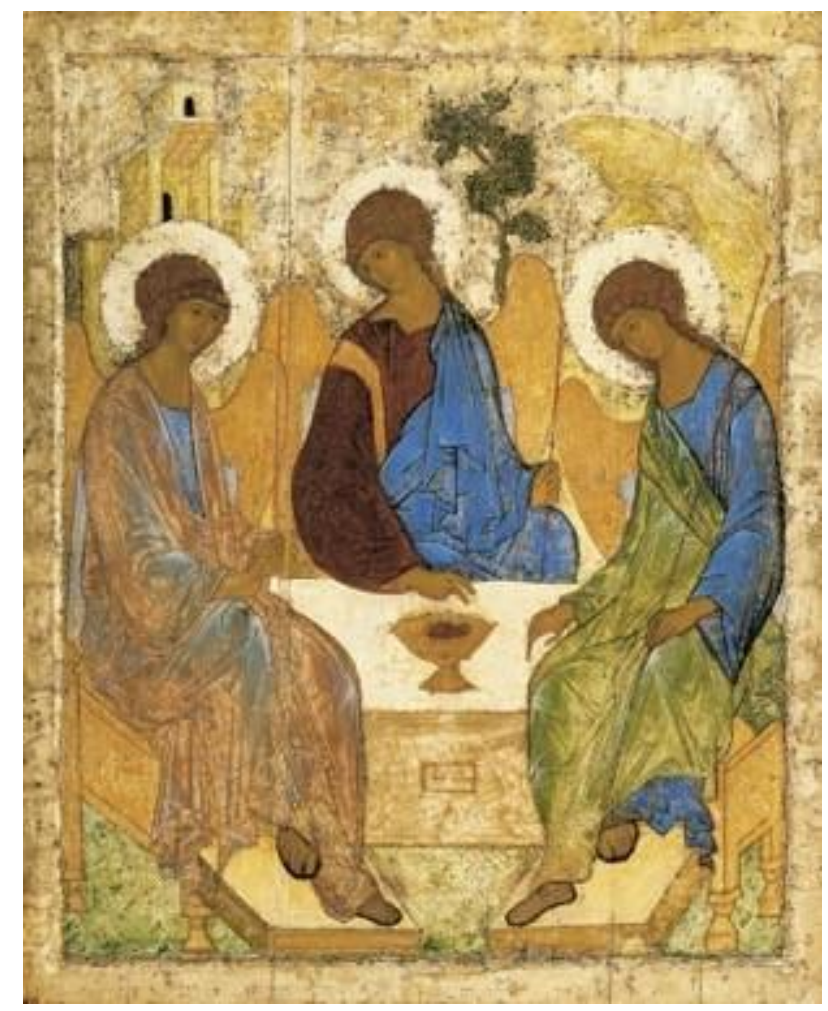

[Fig. 3] Andrei Rublev - La Santísima Trinidad (c. 1410). Fuente:

https://upload.wikimedia.org/wikipedia/commons/0/0b/Angelsatmamre-trinity-rublev-1410.jpg (Consultado:

$15 / 06 / 2017)$

Además, se produce una apropiación de la imagen de San Jorge, actualmente el patrono de Rusia y de la capital desde hace siglos. En los carteles postrevolucionarios, San Jorge es la personificación de "todo el pueblo ruso", representando a todos los bolcheviques frente a la lucha con el dragón, que en este caso es el capitalismo y todas las clases socio-económicas que éste instauró. El dragón es el enemigo, es la imagen de la burguesía y la aristocracia, y están siendo vencidos por el pueblo proletario, esto es, por los bolcheviques. 


\section{Conclusiones}

Hoy en día, el cartel soviético solo es un recuerdo de una época histórica pasada y, en la sociedad rusa, todo lo referente a él se suele analizar desde un punto de vista histórico-artístico por investigadores. Aun así, el cartel ha llegado hasta nosotros como un patrimonio cultural y, además, ha tenido repercusión en los medios de comunicación del siglo XXI, concretamente, en los posters publicitarios.

El cartel como herramienta para difusión de la ideología fue muy una opción apropiada, ya que en Rusia de los años de la Revolución, gran parte de población era analfabeta. Hay que tener en cuenta que hasta el manifiesto proclamado por Alejandro II en 1861, el país era muy atrasado y el sustento principal era la agricultura o la ganadería. Por tanto, las formas de expresión visuales tenían gran poder y facilidad para llegar a ese gran porcentaje de población. Para la difusión de la ideología, los artistas buscaban imágenes o temáticas conocidas a la población para llegar más fácilmente a ellos. La recuperación del icono o de los lubkí y su reformulación hace asimilar más rápido el mensaje que se quería transmitir.

En definitiva, este desarrollo de arte gráfico en Rusia revolucionaria no era la única manera de florecer en el ámbito artístico, pero sí es la más característica, y quizás la más conocida por los lectores. Aunque el presente artículo trata de hacer una introducción a la definición y los antecedentes del cartel soviético, el tema se puede abarcar desde muchas perspectivas diferentes. Y lo más importante es que es un medio que permitía, al menos durante los primeros años postrevolucionarios, crear de manera libre, siguiendo una temática similar, pero eso sí, empleando un lenguaje artístico personal. Tras la muerte de Lenin en 1924, este aspecto poco a poco irá disminuyendo, llegando de este modo a la censura staliniana.

\section{Referencias bibliográficas}

ANDREEVA, Yulia (2009), "Judozhestvennie osobennosti lubochnij tekstov", Vestnik KGY N.A Nekrasova, n³, p. 195-198.

ARAGON, Louis y BRETON, André (1978). Surrealismo frente a Realismo Socialista. Tusquets Editor: Barcelona.

BARNICOAT, John (1972). Los carteles. Su historia y lenguaje. Gustavo Gili: Barcelona. 
BOZAL, Valeriano (1978). El arte del siglo XX. La construcción de la vanguardia (1850-1939).

Vol. 1. Cuadernos para el Diálogo: Madrid.

BÜCHTEN, Danielle (2013). Propaganda! Russian and Norwegian Posters 1920-1939. National Library of Norwegian: Oslo.

CHAUS, Nadezhda (2010), "Sovetskie plakati 1917-1920. Osnovnoe sredstro propagandi sochialisticheskoi ideologii”, Sotsialno-ekonomicheskie iavlenia y progressi, $\mathrm{n}^{\circ} 6, \mathrm{pp} .220$ 223.

GREY, Camilla (1986). The Russian Experiment in Art 1863-1922. Thames and Hudson: Londres. HILTON, Alison (2011). Russian Folk Art. Indiana University Press: Bloomington, Indiana.

KENEZ, Peter (1985). The Birth of the Propaganda State: Soviet Methods of Mass Mobilization, 1917- 1929. Cambridge University Press: Londres.

KOMUNISTICHESKAIA AKADEMIA (1932). Za bolshevistski plakat. Ogiz-Izogiz: MoscúLeningrago.

KURZ MUÑOZ, Juan Alberto (1991). El arte en Rusia. La era soviética. Instituto de Historia del Arte Ruso y Soviético:Valencia.

LECLANCHE-BOULÉ, Claude (2003). Constructivismo en la URSS. Tipografías y fotomontajes. Campgrafic: Valencia.

PAPAIOANNOU, Kostas (1968). Pintura bizantina y rusa. Aguilar: Madrid.

POLONSKY, Viatcheslav (1925). Russkii rebolutsionnii plakat. Gosudarstvennoe izdatelstvo: Moscú.

RENAU, Josep (1976). "El cartel político", Función social del cartel. Fernando Torres Editor: Valencia.

TARABUKIN, Nikolai (1923). Ot molberta do mashini. Rabotnik Prosveschenia: Moscú.

TOLSTOI, Vladimir (2010). Judozhestvennaia zhizn sovetskoi Rossii 1917-1932. Sobitia, fakti, kommentarii. Sbornik materialov y documentov. Galart: Moscú.

TUPITSYN, Margarita (1996). “Abandono de la vanguardia: imaginería soviética bajo Stalin”, Utopia, ilusión y adaptación. Arte soviético 1928-1945. Instituto Valenciano de Arte Moderno: Valencia. 